\title{
Brazilian-Portuguese translation and cross cultural adaptation of the activities-specific balance confidence (ABC) scale
}

\author{
Amelia P. Marques ${ }^{1}$, Yuri C. Mendes ${ }^{1}$, Ulisses Taddei ${ }^{1}$, \\ Carlos A. B. Pereira ${ }^{2}$, Ana Assumpção ${ }^{1}$
}

\begin{abstract}
Background: The Activities-specific Balance Confidence (ABC) scale was developed to quantify the selfperceived level of confidence in performing specific activities without losing balance or becoming unsteady. The ABC scale has been adopted in clinical practice and in research, although cross-cultural differences may impose difficulties in its use. Objective: To translate, cross-culturally adapt and verify the intra- and inter-rater reliability of the BrazilianPortuguese version of the ABC scale and describe the self-perceived balance confidence of elderly Brazilian people. Method: The ABC scale was translated and culturally adapted. To verify the intra- and inter-rater reliability, 40 elderly individuals with ages ranging from 60 to 88 years were interviewed. The scale was administered by two raters on the same day and readministered after seven days by rater 1 . To test the reliability, we used the intraclass correlation coefficient (ICC). Results: Six items from the ABC scale were considered culturally, semantically or regionally inappropriate and were modified. The intra-rater reproducibility was excellent $(\mathrm{ICC}=0.94)$, and the inter-rater reproducibility was very good (ICC $=0.80$ ). The self-perception of balance in specific activities of the elderly was considered very good, with an average of 81.7 and scores ranging from 61.2 to 96.7. Conclusion: The ABC scale was translated and culturally adapted for the Brazilian population and presents good intra- and inter-rater reliability. The self-perceived balance confidence in elderly Brazilian people evaluated with the $\mathrm{ABC}$ scale is moderate.
\end{abstract}

Keywords: physical therapy; reproducibility; balance; fear; elderly.

\section{HOW TO CITE THIS ARTICLE}

Marques AP, Mendes YC, Taddei U, Pereira CAB, Assumpção A. Brazilian-Portuguese translation and cross cultural adaptation of the activities-specific balance confidence (ABC) scale. Braz J Phys Ther. 2013 Mar-Apr; 17(2):170-178. http://dx.doi.org/10.1590/ S1413-35552012005000072

\section{Introduction}

The correct performance of daily life activities, such as walking and manipulating objects, requires good postural control. Self-confidence in executing daily activities is a function that is decreased in the elderly. Furthermore, muscle weakness in the lower limbs ${ }^{1}$, psychological factors, such as depression and anxiety ${ }^{2,3}$, and the presence of chronic, diffuse pain associated with limitation in mobility ${ }^{2}$ have also been identified as important risk factors for falls.

The Activities-specific Balance Confidence (ABC) scale was developed to numerically quantify the level of confidence in performing specific activities without losing balance or becoming unsteady ${ }^{4-7}$. The ABC scale has been adopted in clinical practice and in research, although cross-cultural differences may impose difficulties when using it in different countries. The ABC scale was developed by researchers from the United States ${ }^{6}$, and cultural influences were perceived during its validation for
French-Canadian ${ }^{8}$, Chinese $^{9}$, German $^{10}$, Turkish $^{11}$ and European-Portuguese ${ }^{12}$ populations. The ABC-6 scale, which is a validated, shortened version of the scale, contains only six items ${ }^{13}$.

Until now, no translation or adaptation of the ABC scale has been made for the Brazilian population. Furthermore, while culturally adapting the scale is necessary, it is important that changes do not alter the original intent, which requires it to be broad, comprehensible and applicable to the entire population. As Portuguese is the sixth most-used language in the world, translating and adapting the $\mathrm{ABC}$ scale to the Brazilian population while accounting for its sociocultural characteristics is an important task.

To translate, cross-culturally adapt and verify the intra and inter-rater reliability of the BrazilianPortuguese version of the ABC scale and to describe

${ }^{1}$ Physical Therapy Department, Speech Language and Occupational Therapy. School of Medicine, Universidade de São Paulo (USP), São Paulo, SP, Brazil

${ }^{2}$ Institute of Mathematics and Statistics, Universidade de São Paulo (USP), São Paulo, SP, Brazil

Received 07/29/2012 Revised 10/03/2012 Accepted 11/20/2012 
the self-perceived balance confidence in elderly Brazilian people.

\section{- Method}

The ABC scale is a 16-item questionnaire with 11-point subscales. It can be self-administered or administered by in-person or telephone interviews. Each individual item measures the level of confidence in performing a specific task without losing balance or becoming unsteady by asking participants to assign scores ranging from 0 (no confidence) to $100 \%$ (totally confident). The ABC scale total score is obtained by summing the ratings $(0-1,600)$ and dividing by 16 . The confidence scores are as follows: $>80 \%$ indicates a high level of physical functioning; $50-80 \%$, a moderate level of physical functioning; and $<50 \%$, a low level of physical functioning (Myers et al. ${ }^{5}$ ). Values $<67 \%$ in older adults are predictive of future falls ${ }^{6}$.

Our study consisted of two steps. The first step focused on translation and content equivalence. The second step tested the reliability of the questionnaire and assessed the study participants' balance confidence levels during personal interviews.

\section{Phase 1 - Translation and cultural adaptation}

The steps required for translation and cultural adaptation followed the recommendations of Beaton et al. ${ }^{14}$, Terwee et al. ${ }^{15}$, Maher et al. ${ }^{16}$ and Guillemin et al. ${ }^{17}$ as follows.

1.Translation: Two independent translators translated the ABC scale from English to Brazilian-Portuguese;

2.Translation consolidation: The translators assessed the discrepancies and consolidated the Brazilian-Portuguese version;

3. Back-translation: Two native English-speaking translators independently back-translated the consolidated Brazilian-Portuguese version into English. They did not have access to the original version of the $\mathrm{ABC}$ scale;

4. Final review: A steering committee consisting of the translators, three health professionals (two rheumatologists and one orthopedic surgeon who work with the elderly), two physical therapy researchers and two physical therapy students in the last two years of their graduate programs revised the final version to account for discrepancies and finalized the BrazilianPortuguese version of the $\mathrm{ABC}$ scale, and

5. After the steering committee reached a consensus, the Brazilian-Portuguese version was applied to 20 healthy elderly people by two previously trained raters. The expression "I do not understand" was added to the instructions; questions receiving more than 15\% "I do not understand" answers would be analyzed and replaced with other items of the same concept.

Both raters were physical therapy students who participated in all of the steering committee discussions. Prior to using the Brazilian-Portuguese version, the researcher responsible for the study trained the students and explained how the questions should be formulated to avoid response bias.

The translators were requested to estimate the meaning equivalence for the translated items, both for specific words and for sentences, and account for four specific features: 1) the semantic equivalence of words with similar meanings; 2) the idiomatic equivalence (difficultly in translating) of words proposed and checked by the committee; 3 ) the item equivalence (situations of daily living); and 4) the concept equivalence. The steering committee was asked to endorse the translation for the four aspects. Only the third item of the scale generated discussion among the committee members; two members chose to keep the statement "pick up an object in a closet". In the end, there was consensus to replace this statement with "stooping to pick up an object on the ground," as many people have no closets at home.

The committee discussed the importance of facilitating comprehension when people described their self-perceived balance confidence; therefore, they adopted a graduated scale of 0 to 100 for all items (displaying the $0-100 \%$ scores). The left extremity of the scale anchored on "no confidence" while the right extremity anchored on "completely confident". The scale displayed values in 10-point increments $(0$, 10,20 , etc.). Individuals were instructed to mark only one point on the scale to describe how confident they would be if they had to perform the activity.

\section{Phase 2: Reliability of the ABC scale in brazilian-portuguese}

The final version (Appendix 1) was applied to 40 healthy elderly individuals aged from 60 to 88 years who had the ability to speak and read in Brazilian-Portuguese and had at least four years of formal education. The participants were selected from University employees and from individuals 
accompanying patients attending consultations for physical therapy. All subjects signed approved informed consent forms.

First, we showed and explained the scale scoring system to all of the participants, indicating that the left extremity meant "no confidence" and the right extremity meant "completely confident". The subjects were instructed to circle one of the marks contained on the scale, each spaced $10 \mathrm{~mm}$ apart from one another.

The ABC scale was applied during three assessments; the first two were performed on the same day by two raters ( 1 and 2, inter-rater reliability) at an interval of 30 minutes. The order of the raters was randomized. One week later, rater 1 readministered the questionnaire to estimate the intra-rater reliability (test-retest assessment). In the first evaluation, all of the subjects reported having some difficulty reading or had forgotten their glasses. To standardize the scale application, we chose to read the questions for all of the participants.

The study was approved by the Investigation Review Board of the Clinical Hospital, Universidade de São Paulo (USP), São Paulo, Brazil (0200/08).

\section{Data analysis}

Reliability tests and inferential statistics analysis were performed after confirming a normal distribution (Shapiro-Wilk test) of the items. To verify the interrater reliability, both data sets obtained by raters 1 and 2 were compared using ICC type 3.1. To assess intra-rater reliability, ICC type $2.1 \mathrm{Weir}^{18}$ was used. The significance level was established at 5\%. All statistical tests were applied using SigmaStat 3.5 software, Systat Software Inc., San Jose, California, USA. We used the ICC classification from Wahlund et al. ${ }^{19}$ in which the ICCs $<0.70=$ not acceptable, $0.71<$ ICCs $<0.79=$ acceptable, $0.80<$ ICCs $<0.89=$ =very good, and ICCs $>0.90=$ excellent.

\section{Results}

Forty older adults were included in this study and displayed the following characteristics: $80 \%$ female; aged $74 \pm 4.75$ years; body mass index (BMI) $29.12 \pm 1.88 \mathrm{~kg} / \mathrm{m}^{2}$; educational level $85 \%$ Elementary education; economic status, $20 \%$ economically active, $20 \%$ economically inactive, $30 \%$ retired and $30 \%$ housewives; marital status, $55 \%$ married, $10 \%$ single, $15 \%$ divorced and $20 \%$ widowed.

\section{Translation and cross-cultural adaptation}

Of the 16 original items in the ABC scale, 10 were not modified; six were considered to be culturally, semantically or regionally inappropriate and were modified (Table 1). Question three was modified because many Brazilian people do not have closets in their homes, and the word "slipper" was changed to "object". For question eight, the sentence containing "walk outside the house to a car parked in the driveway" was changed to "walk outside the house to a car or bus stopped in front" to account for differences in socioeconomic levels, as many people do not have cars. For question 10, "walk across a parking lot to the mall" was changed to "walk across a parking lot of a supermarket or a mall". In questions 12 and 13, the word "mall" was replaced by "crowded place" to adjust for cultural differences because many people do not go shopping. In question 16, "walk outside on icy sidewalks" was changed to "walk outside on slippery sidewalk" because snow is extremely rare in Brazil.

Table 2 shows the intra-rater reproducibility of the $\mathrm{ABC}$ scale. The ICC was excellent and very good in 15 items, and only in item 5 was it considered acceptable. The ICC for the total score was excellent (0.94).

Table 3 shows the inter-rater reproducibility of the $\mathrm{ABC}$ scale. The ICC was excellent and very good in

Table 1. Original and six modified items in the cross-cultural adaptation of the ABC scale.

\begin{tabular}{cll}
\hline Items & \multicolumn{1}{c}{ Original Items } & \multicolumn{1}{c}{ Modified Items } \\
3 & $\begin{array}{l}\text { Bend over and pick up a slipper from } \\
\text { the front of a closet floor }\end{array}$ & $\begin{array}{l}\text { Bend over and pick up an object from } \\
\text { the floor }\end{array}$ \\
8 & Walk outside the house to a car parked in the driveway? & Walk outside the house to a car or bus stopped in front \\
10 & Walk across a parking lot to the mall & Walk across a parking lot of a supermarket or a mall \\
12 & Walk in a crowded mall where & Walk in a crowded place where \\
& people rapidly walk past you & people rapidly walk past you \\
13 & $\begin{array}{l}\text { Are bumped into by people as you } \\
\text { walk through the mall" }\end{array}$ & $\begin{array}{l}\text { Are bumped into by people as you } \\
\text { walk through a crowded place }\end{array}$ \\
16 & Walk outside on icy sidewalk & Walk outside on slippery sidewalk \\
\hline
\end{tabular}


Table 2. Intra-rater reproducibility: Mean (Standard error), intraclass correlation (ICC) and p-values of the 16-item ABC scale.

\begin{tabular}{|c|c|c|c|c|}
\hline $\begin{array}{c}\text { ABC } \\
\text { Scale } \\
\text { (Items) }\end{array}$ & $\begin{array}{c}\text { Evaluation } 1 \\
\text { Mean (SE) }\end{array}$ & $\begin{array}{c}\text { Evaluation } 2 \\
\text { Mean (SE) }\end{array}$ & ICC & $\mathbf{p}^{1}$ \\
\hline 1 & $88.2(0.9)$ & $90.5(1.1)$ & 0.89 & 0.315 \\
\hline 2 & $85.5(1.3)$ & $87.7(1.0)$ & 0.90 & 0.293 \\
\hline 3 & $86.2(1.2)$ & $88.2(0.9)$ & 0.84 & 0.623 \\
\hline 4 & $93.5(0.8)$ & $93.0(1.0)$ & 0.90 & 0.766 \\
\hline 5 & 80.5 (1.6) & $85.0(0.8)$ & 0.71 & 0.743 \\
\hline 6 & $68.5(1.1)$ & $67.5(0.9)$ & 0.85 & 0.332 \\
\hline 7 & $96.7(0.4)$ & $95.2(1.3)$ & 0.90 & 0.089 \\
\hline 8 & $87.2(1.8)$ & $89.2(0.9)$ & 0.92 & 0.509 \\
\hline 9 & $86.5(1.1)$ & $91.7(0.9)$ & 0.87 & 0.667 \\
\hline 10 & $89.7(0.9)$ & $92.7(0.8)$ & 0.88 & 0.412 \\
\hline 11 & 81.5 (1.9) & $81.5(1.0)$ & 0.89 & 0.326 \\
\hline 12 & $84.0(0.9)$ & $82.7(1.1)$ & 0.80 & 0.567 \\
\hline 13 & $79.5(0.9)$ & 78.7 (0.9) & 0.97 & 0.476 \\
\hline 14 & 76.7 (1.4) & 74.5 (1.0) & 0.90 & 0.876 \\
\hline 15 & $63.2(1.0)$ & $60.2(1.0)$ & 0.96 & 0.374 \\
\hline 16 & $61.2(0.9)$ & $63.0(0.9)$ & 0.97 & 0.841 \\
\hline ABC total & $81.7(1.5)$ & $83.8(1.7)$ & 0.94 & 0.438 \\
\hline CI & (78.6-84.9) & (80.4-87.2) & & \\
\hline
\end{tabular}

${ }^{1}$ two-way analysis of variance (Anova). Standard error (SE); Confidence interval (CI).

most items, and in only four items was it considered acceptable (items 3, 7, 11 and 15). The ICC for the total score was very good (0.80).

\section{Self-perceived balance confidence of elderly people}

The mean perceived balance confidence level of the elderly was 81.7 , with scores ranging from 61.2 to 96.7 , indicating a moderate level of physical functioning. The highest confidence level was found for balance associated with "sweep the floor" (item 7), and the lowest was for "walk outside on slippery sidewalk" (item 16) and "step onto or off an escalator while holding onto parcels such that you cannot hold onto the railing" (item 15).

\section{Discussion}

The objective of this study was to translate, crossculturally adapt and verify the intra- and inter-rater reliability of the Brazilian-Portuguese version of the $\mathrm{ABC}$ scale and to describe the self-perceived balance confidence in elderly Brazilian people. Our results showed that intra-rater and inter-rater reproducibility was very good, and the elderly showed a moderate self-perceived balance confidence.

Adapting the ABC scale is necessary, and it is important not alter the original intent. The adaptation must be comprehensible and applicable to the entire population, while accounting for sociocultural characteristics. We believe that verifying reproducibility is most important to the quality of the Brazilian Portuguese version of the questionnaire. However, attention must be given to the variability that can occur in symptomatology because of the interval between the two applications of the questionnaire ${ }^{20,16}$.

The original version of the $\mathrm{ABC}$ scale was written in English and targeted the Canadian population. Changes were necessary to adapt specific items to the Brazilian geography (e.g., weather) as well as the socio-demographic reality of the country. The Human Development Index (HDI) is $0.772 ; 7.7 \%$ of the adult population is illiterate, and the overall mean number of school years is $6.5^{21,22}$. In addition, 
Table 3. Inter-rater reproducibility: Mean (Standard error), intraclass correlation (ICC) and p-values of the 16-item ABC scale.

\begin{tabular}{|c|c|c|c|c|}
\hline $\begin{array}{c}\text { ABC } \\
\text { Scale } \\
\text { (Items) }\end{array}$ & $\begin{array}{c}\text { Rater } 1 \\
\text { Mean (SE) }\end{array}$ & $\begin{array}{c}\text { Rater } 2 \\
\text { Mean (SE) }\end{array}$ & ICC & $\mathbf{p}^{1}$ \\
\hline 1 & $88.2(0.9)$ & $88.2(1.0)$ & 0.99 & 0.546 \\
\hline 2 & $85.5(1.3)$ & $82.0(1.2)$ & 0.93 & 0.672 \\
\hline 3 & $86.2(1.2)$ & 88.7 (1.0) & 0.79 & 0.770 \\
\hline 4 & $93.5(0.8)$ & 92.7 (1.0) & 0.80 & 0.122 \\
\hline 5 & 80.5 (1.6) & $78.2(1.0)$ & 0.88 & 0.345 \\
\hline 6 & $68.5(1.1)$ & $68.0(1.0)$ & 0.91 & 0.632 \\
\hline 7 & $96.7(0.4)$ & $90.0(0.9)$ & 0.79 & 0.125 \\
\hline 8 & $87.2(1.8)$ & $86.0(1.0)$ & 0.81 & 0.646 \\
\hline 9 & $86.5(1.1)$ & 87.5 (1.0) & 0.89 & 0.196 \\
\hline 10 & $89.7(0.9)$ & $89.0(1.1)$ & 0.87 & 0.171 \\
\hline 11 & 81.5 (1.9) & $80.0(0.9)$ & 0.72 & 0.895 \\
\hline 12 & $84.0(0.9)$ & $84.0(1.0)$ & 0.90 & 0.660 \\
\hline 13 & $79.5(0.9)$ & 80.7 (1.0) & 0.92 & 0.667 \\
\hline 14 & 76.7 (1.4) & $73.0(1.0)$ & 0.88 & 0.412 \\
\hline 15 & $63.2(1.0)$ & $58.0(1.0)$ & 0.73 & 0.326 \\
\hline 16 & $61.2(0.9)$ & $60.7(1.0)$ & 0.90 & 0.567 \\
\hline ABC total & 81.7 (1.5) & $81.7(1.6)$ & 0.80 & 0.570 \\
\hline CI & (78.6-84) & $(79.4-84)$ & & \\
\hline
\end{tabular}

${ }^{1}$ two-way analysis of variance (Anova). Standard error (SE); Confidence interval (CI).

the purchasing power of Brazilians is still low when compared to other countries.

Of the 16 original items, six were modified because they focused on situations with which many Brazilians may be unfamiliar. There was a need to adapt to the local reality, which is different from that of the Canadian population. In doing so, we guaranteed that comprehension of all items was adequate, and we demonstrated that the process used in the translation and adaptation was efficient for all of the specific items. For example, in item 8 , the sentence containing "walk outside the house to a car parked in the driveway" was changed to "walk outside the house to a car or bus stopped in front" to account for differences in socioeconomic levels. In questions 10, 12 and 13, we changed the words to adjust for cultural differences because many people do not go shopping and snow is extremely rare in Brazil.

We also modified item 3 and changed "pick up a slipper" to "pick up an object on the floor" because many houses in Brazil do not have closets, a fact that could hinder comprehension. When the scale was applied, none of the respondents reported doubts as to the contents asked; the scores for this item were similar in the three studies (Brazilian, Chinese and Canadian), which indicates that this modification did not change its meaning (Table 4).

In the studies of the Brazilian-Portuguese, Chinese and original versions, the items with the lowest degrees of confidence were identical: item 6 (stand on a chair and reach for something), 15 (step onto or off an escalator while holding onto parcels such that you cannot hold onto the railing?) and 16 (walk outside on icy sidewalks). These items had the lowest scores, with values ranging from 61.2 to $68.5 \%$. However, these questions have also been associated with lower values in other studies ${ }^{8,9,13,23}$.

The mean values found in the Brazilian and Chinese studies were more similar than those observed in the Canadian study for most items. The mean level of self-perceived balance confidence that we observed in older Brazilian adults (81.7) is higher than the one obtained in the study using the original version (59.6) but similar to the study of the Chinese version for most of the questions. Such a difference may be explained by the type of the population 
Table 4. Comparison of the Brazilian ABC score with the Chinese and the original English version.

\begin{tabular}{cccc}
\hline Items & $\begin{array}{c}\text { Brazilian ABC Score } \\
(\mathbf{n = 4 0})\end{array}$ & $\begin{array}{c}\text { Chinese ABC Score } \\
\text { Mean }\end{array}$ & $\begin{array}{c}\text { Mean }) \\
\text { Original ABC Score } \\
(\mathbf{n}=\mathbf{6 0})\end{array}$ \\
Mean \\
2 & 88.2 & 89.9 & 87.5 \\
3 & 85.5 & 80.5 & 64.8 \\
4 & 86.2 & 74.1 & 62.8 \\
5 & 93.5 & 81 & 89.5 \\
6 & 80.5 & 65 & 46.5 \\
7 & 68.5 & 56.7 & 38 \\
8 & 96.7 & 77.9 & 66.8 \\
9 & 87.2 & 82 & 71.6 \\
10 & 86.5 & 81.2 & 78.5 \\
11 & 89.7 & 75.6 & 67.7 \\
12 & 81.5 & 73.9 & 61 \\
13 & 84.0 & 67.8 & 62.2 \\
14 & 79.5 & 59.9 & 53 \\
15 & 76.7 & 78.6 & 52.3 \\
16 & 63.2 & 48.4 & 31.3 \\
Total score (SD) & 61.2 & 57.2 & 20.7 \\
\hline
\end{tabular}

$\mathrm{SD}=$ Standard deviation.

studied using the original version, which included individuals with stroke who previously had a decrease in postural control ${ }^{7}$.

Despite cultural differences, items 6, 15 and 16, are difficult tasks to perform. Among the elderly, especially those with some sequelae, this matter is often raised in routine practice ${ }^{8}$. These findings may be explained by the increased complexity of making judgment calls to specific tasks that may not be part of the daily routine of the participants (e.g., stepping onto or off an escalator while holding onto parcels such that you cannot hold onto the railing, or walking on a slippery sidewalk). Values lower than $<67 \%$ indicate older adults at risk of falling ${ }^{6}$. In our study, only three items presented a score lower than $67 \%$; in the study of the Chinese version and the original $\mathrm{ABC}$ scale, there were five and twelve items, respectively.

In our study, the intra-rater reproducibility for the total score was excellent (ICC $=0.94$ ). For each item, the ICC values ranged from 0.71 to 0.97 , with the lowest score for item 5 (stand on your tip toes and reach for something above your head) and the highest for items 13 and 16. For inter-rater reproducibility, the ICC was very good (0.80); the values ranged from 0.72 to 0.99 , with item 1 being the highest rated and item 11 the lowest. Similar results were found by other investigators, such as Mak et al. ${ }^{9}$, who obtained an excellent ICC. Additionally, Schepens et al. ${ }^{13}$ investigated whether the short version of the $\mathrm{ABC}$ scale (ABC-6) was valid and reliable for measuring balance confidence and examined its relationship to balance impairment and falls in older adults. Schepens found good and excellent rater test-retest reliability in the two $\mathrm{ABC}$ scales.

The intra-rater and inter-rater reproducibility was very good or excellent for almost all items, and thus, we conclude that the scale can be used in clinical or research situations. The comprehension of the $\mathrm{ABC}$ scale may have been enhanced by the fact that it was applied by in-person interviews, and when the respondents had doubts, they were immediately clarified by the interviewer.

When we concluded the translation and cultural adaptation, we decided to modify the form of responses to increase comprehension when people describe the self-perceived balance confidence. In this 
regard, we decided to include a 0 to $100 \%$ graduated scale for all items, with 10-point increments (10\% intervals), for a total of 11 points. Moreover the individuals were instructed to mark only one point on the scale. We believe that this procedure may have facilitated understanding; the participants quickly understood and marked their self-perceived balance confidence on the scale.

\section{Study limitations}

The study had the following limitations: the ABC scale was applied to a small sample (40 subjects) to assess intra-and inter-rater reliability, limiting the power of generalization. The committee members had no cultural experience in Canada, the country where the scale originated. Another limitation was the lack of a pretest containing questions to assess interpretation, as suggested by Guillemin et al. ${ }^{17}$.

\section{Clinical relevance}

The ABC scale seems to be a powerful tool for use in Brazil in clinical practice and research. It should target the elderly population and provide data that will guide preventive initiatives or interventions tailored to restore the self-confidence of this population. Assessing the fear of falling is an important procedure, as fear is, per se, a risk factor for limitations and falls. The ABC scale allows the assessment of specific matters in the daily lives of people, particularly the elderly, and this assessment may lead to physical therapy intervention for specific activities. Furthermore, interventions that reduce fear and insecurity may translate into improved balance confidence and better quality of life. We suggest that the Brazilian version be applied by trained raters instead of self-administered by healthy elderly individuals.

\section{Conclusion}

The ABC scale was translated and culturally adapted for the Brazilian population. When applied by trained raters, the $\mathrm{ABC}$ scale presents very good intra and inter-rater reliability in the healthy elderly population. The self-perceived balance confidence in elderly Brazilian people evaluated with the $\mathrm{ABC}$ scale was moderate.

\section{References}

1. Moreland JD, Richardson JA, Goldsmith $\mathrm{CH}$, Clase CM, Chir B. Muscle weakness and falls in older adults: a systematic review and meta-analysis.
J Am Geriatr Soc. 2004;52(7):1121-9. http://dx.doi. org/10.1111/j.1532-5415.2004.52310.x

2. Leveille SG, Bean J, Bandeen-Roche K, Jones R, Hochberg M, Guralnik JM. Musculoskeletal pain and risk for falls in older disabled women living in the community. J Am Geriatr Soc. 2002;50(4):671-8. http://dx.doi. org/10.1046/j.1532-5415.2002.50161.x

3. Bergland A, Wyller TB. Risk factors for serious fall related injury in elderly women living at home. Inj Prev. 2004;10(5):308-13. http://dx.doi.org/10.1136/ ip.2003.004721

4. Powell LE, Myers AM. The Activities-specific Balance Confidence (ABC) Scale. J Gerontol A Biol Sci Med Sci. 1995;50(1):28-34. http://dx.doi.org/10.1093/ gerona/50A.1.M28

5. Myers AM, Fletcher PC, Myers AH, Sherk W. Discriminative and Evaluative Properties of the Activitiesspecific Balance Confidence (ABC) Scale. J Gerontol A Biol Sci Med Sci. 1998;53(4):287-94. http://dx.doi. org/10.1093/gerona/53A.4.M287

6. Lajoie Y, Girard A, Guay M. Comparision of the reaction time, the Berg Scale and the ABC in non-fallers and fallers. Arch Gerontol Geriatr. 2002;35(3):215-25. http://dx.doi. org/10.1016/S0167-4943(02)00027-4

7. Lajoie Y, Gallagher SP. Predicting falls within the elderly community: comparison of postural sway, reaction time the Berg balance scale and the Activities-specific Balance Confidence $(\mathrm{ABC})$ scale for comparing fallers and nonfallers. Arch Gerontol Geriatr. 2004;38(1):11-26. http:// dx.doi.org/10.1016/S0167-4943(03)00082-7

8. Salbach NM, Mayo NE, Hanley JA, Richards CL, WoodDauphinee S. Psychometric evaluation of the original and Canadian French version of the activities-specific balance confidence scale among people with stroke. Arch Phys Med Rehabil. 2006;87(12):1597-604. http://dx.doi. org/10.1016/j.apmr.2006.08.336

9. Mak MK, Lau AL, Law FS, Cheung CC, Wong IS. Validation of the Chinese Translated ActivitiesSpecific Balance Confidence Scale. Arch Phys Med Rehabil. 2007;88(4):496-503. http://dx.doi.org/10.1016/j. apmr.2007.01.018

10. Schott N. German adaptation of the ActivitiesSpecific Balance Confidence (ABC) scale for the assessment of falls-related self-efficacy. Z Gerontol Geriatr. 2008;41(6):475-85. http://dx.doi.org/10.1007/ s00391-007-0504-9

11. Karapolat H, Eyigor S, Kirazli Y, Celebisoy N, Bilgen C, Kirazli T. Reliability, validity, and sensitivity to change of Turkish Activities-specific Balance Confidence Scale in patients with unilateral peripheral vestibular disease. Int J Rehabil Res. 2010;33(1):12-8. http://dx.doi.org/10.1097/ MRR.0b013e32832c0d72

12. Branco PS. Validação da versão Portuguesa da "Activitiesspecific Balance Confidence Scale". Rev Soc Port Med Fís Reabil. 2010;19(2):20-25.

13. Schepens S, Goldberg A, Wallace M. The short version of the Activities-specific Balance Confidence (ABC) Scale: its validity, reliability, and relationship to balance impairment and falls in older adults. Arch Gerontol 
Geriatr. 2010;51(1):9-12. http://dx.doi.org/10.1016/j. archger.2009.06.003

14. Beaton DE, Bombardier C, Guillemin F, Ferraz MB. Guidelines for the process of cross-cultural adaptation of self-report measures. Spine. 2000;25(24):3186-91. http:// dx.doi.org/10.1097/00007632-200012150-00014

15. Terwee CB, Bot SD, De Boer MR, Van der Windt DA, Knol DL, Dekker J, et al. Quality criteria were proposed for measurement properties of health status questionnaires. J Clin Epidemiol. 2007;60(1):34-42. http://dx.doi. org/10.1016/j.jclinepi.2006.03.012

16. Maher CG, Latimer J, Costa LOP. The relevance of crosscultural adaptation and clinimetrics for physical therapy instruments. Rev Bras Fisioter. 2007;11(4):245-52. http:// dx.doi.org/10.1590/S1413-35552007000400002

17. Guillemin F, Bombardier C, Beaton D. Cross-cultural adaptation of health-related quality of life measures: literature review and proposed guidelines. J Clin Epidemiol. 1993;46(12):1417-1432. http://dx.doi. org/10.1016/0895-4356(93)90142-N

18. Weir JP. Quantifying test-retest reliability using the intraclass correlation coefficient and the SEM. J Strength Cond Res. 2005;19(1):231-40.

19. Wahlund K, List T, Dworkin SF. Temporomandibular disorders in children and adolescents: reliability of a questionnaire, clinical examination, and diagnosis. J Orofac Pain. 1998;12(1):42-51. PMID:9656898
20. Campos JADB, Carrascosa AC, Loffredo LCM, Faria JB. Consistência interna e reprodutibilidade da versão em português do critério de diagnóstico na pesquisa para desordens temporomandibulares (RDC/TMD - Eixo II). Rev Bras Fisioter. 2007;11(6):451-459. http://dx.doi. org/10.1590/S1413-35552007000600006

21. Leal MCC, Marques APO, Marino JG, Rocha EC, Santos $\mathrm{CR}$, Austregésilo SC. Perfil de pacientes idosos e tempo de permanência em ambulatório geronto-geriátrico. Rev Bras Geriatr Gerontol. 2009;12(1):77-86.

22. Instituto Brasileiro de Geografia e Estatística - IBGE. Perfil dos Idosos Responsáveis pelos Domicílios [Internet]. Available from: http://www.ibge.gov.br/home/presidencia/ noticias/25072002pidoso.shtm.

23. Botner EM, Miller WC, Eng JJ. Measurement properties of the Activities-specific Balance Confidence Scale among individuals with stroke. Disabil Rehabil. 2005;27(4):156-63. http://dx.doi. org/10.1080/09638280400008982

\section{Correspondence}

\section{Amélia Pasqual Marques}

Rua Cipotânea, 51, Cidade Universitária

CEP 05360-160, São Paulo, Brasil

e-mail: pasqual@usp.br 


\section{Appendix}

Appendix 1. The Activities-specific Balance Confidence (ABC) Scale for Brazilian-Portuguese Each item bellow has one line with values ranging from 0 to $100 \%$. Please, check your confidence level remembering $0 \%$ indicates no confidence and $100 \%$ total confidence.

1. Andar pela casa

2. Subir ou descer uma escada

3. Abaixar-se para pegar um objeto no chão

4. Pegar uma latinha numa prateleira na altura dos olhos

5. Ficar na ponta dos pés para pegar algum objeto acima da cabeça

6. Subir numa cadeira para pegar algo

7. Varrer o chão

8. Sair de casa e andar até um carro ou ônibus parado em frente

9. Entrar ou sair de um carro

10. Atravessar um estacionamento de um supermercado ou shopping 0

11. Subir ou descer uma rampa

12. Andar em um lugar movimentadoonde as pessoas passavam rápido por você

13. Esbarrarem em você em um lugar movimentado, cheio de gente

14. Pegar ou sair de uma escada rolante segurando no corrimão

15. Pegar ou sair de uma escada rolante carregando pacotes e sacolas 0 que o(a) impedem de segurar o corrimão

16. Andar em calçada molhada ou escorregadia

\section{Sem Confiança \\ Confiança Total}

0

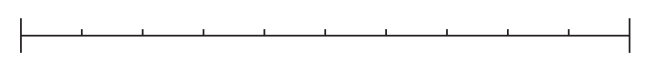

$0 \quad 100$

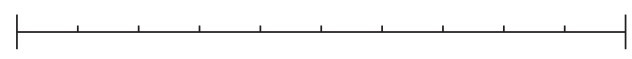

0

100
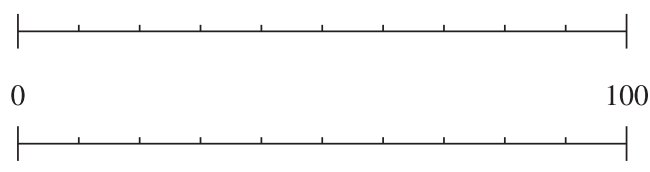

0

100

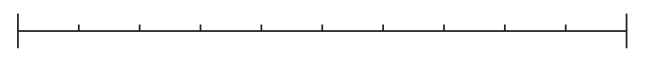

$0 \quad 100$
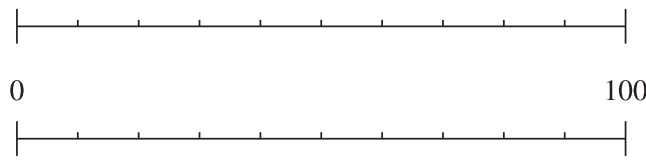

$0 \quad 100$

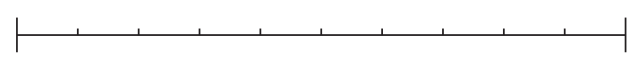

$0 \quad 100$

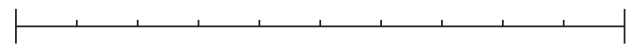

$0 \quad 100$
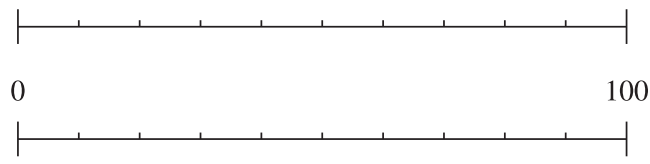

$0 \quad 100$

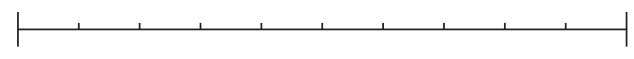

$0 \quad 100$

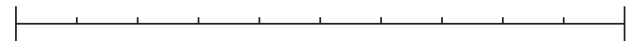

$0 \quad 100$

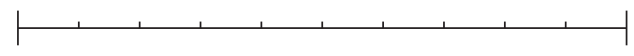

100

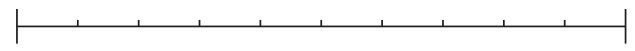

$0 \quad 100$

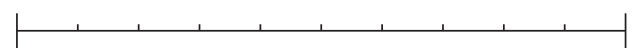

